\section{Acute intraoperative suprachoroidal haemorrhage in ocular surgery}

\begin{abstract}
Purpose/Background Acute intraoperative suprachoroidal haemorrhage (AISH) is the most sight-threatening complication of ocular surgery. We investigated the visual outcomes following this intraoperative event, patient characteristics that may predispose to it and the clinical features that may be of prognostic significance.

Methods The records of 45 cases of AISH collected from ophthalmic centres in the United Kingdom, Republic of Ireland and Switzerland were reviewed. Two satisfactory controls in terms of operative procedure, surgeon, age ( \pm 5 years) and gender were found for each of $\mathbf{3 3}$ of our cases. Systemic and ocular characteristics were compared for cases and controls, and the visual results of all cases of AISH are analysed.
\end{abstract}

Results Cases and controls differed only in terms of axial length and pre-operative intraocular pressure, both of which were significantly greater for eyes that experienced an AISH $(p<0.05)$. Ten eyes $(22.2 \%)$ achieved a final Snellen acuity of $6 / 12$ or better. Statistically significant associations with a final acuity of counting fingers or worse included spontaneous nuclear expression ( $p=0.02)$, retinal detachment $(p<0.0001)$, fourquadrant suprachoroidal haemorrhage $(p=0.007)$ and vision of perception of light or worse at the first dressing $(p=0.0001)$. Four of the 6 eyes that experienced an AISH during phacoemulsification surgery had a visual outcome of $6 / 12$ or better, and this was significantly greater than for cases involving extracapsular cataract surgery $(p=0.004)$. Conclusion The results indicate that longer axial length and higher pre-operative intraocular pressure are associated with increased risk of AISH. Poor visual results are more likely following spontaneous nuclear expression, retinal detachment, four-quadrant suprachoroidal haemorrhage or vision of perception of light or worse at the first dressing. The results also suggest that AISH complicating a phacoemulsification procedure has a more favourable visual prognosis than AISH that occurs during extracapsular cataract surgery.
S. BEATTY, A. LOTERY, D. KENT,

A. O'DRISCOLL, D.J. KILMARTIN,

D. WALLACE, E. BAGLIVO

Key words Expulsive, Haemorrhage,

Phacoemulsification, Suprachoroidal

Suprachoroidal haemorrhage may occur spontaneously, ${ }^{1-3}$ intraoperatively ${ }^{4,5}$ or postoperatively. ${ }^{6,7}$ Acute intraoperative suprachoroidal haemorrhage (AISH) is a potentially blinding condition and is perhaps the complication ophthalmic surgeons fear most. The low incidence of this intraoperative event, although comforting to ophthalmologists, has resulted in a paucity of large published series and consequently much of our information regarding AISH is anecdotal. The current study is the result of multicentre collaboration and allows us to report on the risk factors, prognostic indicators and visual outcomes of 45 cases of AISH.

\section{Patients and methods}

Cases of AISH were collected from four regions in the United Kingdom, one centre in the Republic of Ireland and one in Switzerland. We involved several hospitals in this retrospective study because we were investigating a serious intraoperative complication with an inherently low incidence, and a large number of cases were required for statistical analysis. These particular centres were selected because the main author (S.B.) was personally acquainted with a member of the ophthalmic staff in each region.

AISH was defined as surgeon-diagnosed acute intraoperative suprachoroidal haemorrhage and all cases included at least two of the following intraoperative signs: shallowing of the anterior chamber; wrinkling of the posterior capsule; iris prolapse; hardening of the eye; loss of red reflex; choroidal effusion; spontaneous nuclear expression; extrusion of intraocular contents. Each AISH was then classed as either expulsive or non-expulsive. Expulsive cases included those with spontaneous nuclear expression and/or extrusion of intraocular contents, and the event was described as non-expulsive in the absence of these signs.
S. Beatty

A. O'Driscoll

Birmingham and Midland Eye Centre Birmingham, UK

A. Lotery Department of Ophthalmology Royal Victoria Hospital Belfast, Northern Ireland

D. Kent

St Paul's Eye Unit

Royal Liverpool University Hospital

Liverpool, UK

D.J. Kilmartin Aberdeen Royal Infirmary Aberdeen, UK

D. Wallace Royal Victoria Eye and Ear Hospital

Dublin, Ireland

E. Baglivo

Clinique d'Ophtalmologie Universitaire de Genève

Geneva, Switzerland

S. Beatty

Manchester Royal Eye

Hospital

Oxford Road

Manchester M13 9WH, UK

Tel: $+44(0) 1618817119$

e-mail: stephen@

stiofanbetagh.demon.co.uk 
To investigate possible risk-factors for AISH we matched each case to two randomly selected, uneventful but identical operative procedures by the same surgeon. Cases and controls were also matched for age ( \pm 5 years) and gender.

Data retrieved for each case and control may be divided into pre-operative, intraoperative and postoperative. Pre-operative data included age, gender, race, ocular co-morbidity, past medical history, drug therapy, axial length and last recorded intraocular pressure (IOP) of the operated eye. We recorded the following intraoperative details: eye (right or left); type of anaesthesia, including use of eyelid akinesia; grade of operating surgeon; operative procedure; fixation sutures; safety sutures; type and size of incision; type of viscoelastic; type of capsulotomy; stage and mode of presentation of AISH; intraoperative management. Postoperative information that we collected comprised clinical and therapeutic details, ultrasonographic findings and visual outcomes.

All data were analysed in a fashion appropriate to the clinical setting. For example, the potential protective effect of eyelid akinesia was assessed by comparing its use only among those cases and controls in which regional anaesthesia was employed. The significance of associations between categories was tested using the chisquared test, or Fisher's exact test where expected values were less than 5. Statistical comparisons of paired numerical data were made using the non-parametric Wilcoxon signed rank test.

\section{Results}

We collected 45 cases of AISH from four regions within the United Kingdom, one centre in the Republic of Ireland and one in Switzerland. Thirty-four of the patients were women; ages ranged from 47 to 94 years (mean \pm SD: $74.2 \pm 12.1$ years) and follow-up varied from 3 months to $61 / 2$ years.

Satisfactory controls with respect to age, gender, operating surgeon and intraocular procedure were found for 33 cases. The demographic, pre-operative and peroperative details of cases and controls are given in Tables 1 and 2 . The incidence of cardiovascular disease, chronic obstructive airways disease, diabetes mellitus, glaucoma and the use of anticoagulants were statistically similar for the two groups (Table 1). Operative details in terms of anaesthesia, use of fixation and stay sutures, type and size of section, variety of capsulotomy, and type of viscoelastic substance did not differ significantly between cases and controls (Table 2). However, significantly greater axial lengths and pre-operative IOPs were noted for eyes in the AISH group than for those in the control group (Table 1).

Demographic data, operative procedures and final visual outcomes of all 45 cases of AISH are given in Table 3. Intraoperative details are shown in Table 4. Twentytwo cases $(48.5 \%)$ were classed as expulsive, and the remainder were non-expulsive. Clinical findings on the first post-operative day included: shallow anterior chamber (20 cases; $44.4 \%$ ); retinal detachment (16 cases; $35.5 \%)$; vitreous haemorrhage (9 cases; $20 \%$ ); IOP>21 $\mathrm{mmHg}$ (15 cases; $33 \%$ ); Snellen acuity of counting fingers (CF) or worse in the operated eye (42 patients; $93.3 \%$ ). Final visual outcomes are displayed histographically in Fig. 1. A favourable final Snellen acuity of $6 / 12$ or better was seen in 10 patients $(22.2 \%)$, final acuities varying between $6 / 18$ and $6 / 60$ were achieved in 8 patients $(17.7 \%)$ and the remainder had vision of CF or worse at the last assessment (27 patients; $60 \%$ ).

Final visual outcomes were unrelated to the following per-operative data: type of anaesthesia $(p=0.66)$; use of safety sutures in cataract surgery $(p=0.29)$;

Table 1. Per-operative details for 33 cases of acute intraoperative suprachoroidal haemorrhage and 66 matched controls

\begin{tabular}{|c|c|c|c|c|}
\hline & AISH cases $(n=33)$ & Controls $(n=66)$ & $\chi^{2}$ or $t$ & $p$ value \\
\hline $\begin{array}{l}\text { Demographic data } \\
\text { Age (years) } \\
\text { Gender (male:female) }\end{array}$ & $\begin{array}{l}77.3 \pm 11.3 \\
6: 27\end{array}$ & $\begin{array}{l}78.1 \pm 7.6 \\
6: 27\end{array}$ & $t=-0.75$ & 0.45 \\
\hline $\begin{array}{l}\text { Systemic disease } \\
\text { Cardiovascular disease, including hypertension } \\
\text { Diabetes mellitus } \\
\text { COAD }\end{array}$ & $\begin{aligned} 15 & (45 \%) \\
4 & (12.1 \%) \\
3 & (9.1 \%)\end{aligned}$ & $\begin{aligned} 23 & (34.8 \%) \\
11 & (16.6 \%) \\
1 & (3.3 \%)\end{aligned}$ & $\begin{array}{l}\chi^{2}=1.05 \\
\chi^{2}=0.35 \\
\chi^{2}=3.26\end{array}$ & $\begin{array}{l}0.3 \\
0.55 \\
0.1\end{array}$ \\
\hline $\begin{array}{l}\text { Use of anticoagulant or anti-platelet therapy } \\
\text { Warfarin } \\
\text { Aspirin }\end{array}$ & $\begin{array}{l}8(24.2 \%) \\
2(6 \%) \\
6(18.2 \%)\end{array}$ & $\begin{array}{l}7(10.6 \%) \\
3(4.5 \%) \\
4(6.06 \%)\end{array}$ & $\begin{array}{l}\chi^{2}=3.18 \\
\chi^{2}=0.1 \\
\chi^{2}=3.56\end{array}$ & $\begin{array}{r}0.07 \\
>0.99 \\
0.08\end{array}$ \\
\hline $\begin{array}{l}\text { Operated eye } \\
\text { Right:left }\end{array}$ & 18:15 & $33: 33$ & $\chi^{2}=0.18$ & 0.67 \\
\hline $\begin{array}{l}\text { Ocular co-morbidity } \\
\text { Glaucoma } \\
\text { Previous intraocular surgery }\end{array}$ & $\begin{array}{c}20(60.6 \%) \\
2(6 \%)\end{array}$ & $\begin{array}{r}29(43.9 \%) \\
6(9.09 \%)\end{array}$ & $\begin{array}{l}\chi^{2}=2.44 \\
\chi^{2}=0.6\end{array}$ & $\begin{array}{l}0.12 \\
0.27\end{array}$ \\
\hline Last recorded IOP (mean $\pm \mathrm{SD})$ & $\begin{array}{l}21.09 \pm 10.18 \mathrm{mmHg} \\
\text { (range: } 11-72 \mathrm{mmHg} \text { ) }\end{array}$ & $\begin{array}{l}17.66 \pm 5.8 \mathrm{mmHg} \\
\text { (range: } 8-45 \mathrm{mmHg} \text { ) }\end{array}$ & $t=3.66$ & 0.0005 \\
\hline Axial length (mean $\pm \mathrm{SD})$ & $\begin{array}{l}23.33 \pm 1.32 \mathrm{~mm} \\
\text { (range: } 21.4-26.2 \mathrm{~mm} \text { ) }\end{array}$ & $\begin{array}{l}22.9 \pm 1.25 \mathrm{~mm} \\
\text { (range: } 21.069-26.65 \mathrm{~mm} \text { ) }\end{array}$ & $t=2.28$ & 0.026 \\
\hline
\end{tabular}

COAD, chronic obstructive airways disease; IOP, intraocular pressure; SD, standard deviation. 
Table 2. Intra-operative details for 33 cases of acute intraoperative suprachoroidal haemorrhage and 66 matched controls

\begin{tabular}{|c|c|c|c|c|}
\hline & AISH cases $(n=33)$ & Controls $(n=66)$ & $\chi^{2}$ or $t$ & $p$ value \\
\hline $\begin{array}{l}\text { Type of anaesthesia } \\
\text { GA:LA } \\
\text { GA } \\
\text { Peribulbar } \\
\text { Retrobulbar }\end{array}$ & $\begin{array}{l}8: 25 \\
8(24.2 \%) \\
14(42.4 \%) \\
11(33.3 \%)\end{array}$ & $\begin{array}{l}18: 48 \\
18(27.2 \%) \\
36(54.5 \%) \\
12(18.2 \%)\end{array}$ & $\begin{array}{l}\chi^{2}=0.74 \\
\chi^{2}=2.9\end{array}$ & 0.23 \\
\hline $\begin{array}{l}\text { Facial nerve block } \\
\text { (for local anaesthesia only) }\end{array}$ & $5 / 25(20 \%)$ & $11 / 48(23 \%)$ & $\chi^{2}=0.034$ & 0.85 \\
\hline Superior rectus fixation suture & $27(81.8 \%)$ & $48(72.7 \%)$ & $\chi^{2}=0.577$ & 0.45 \\
\hline $\begin{array}{l}\text { Section } \\
\text { Corneal } \\
\text { Limbal } \\
\text { Scleral }\end{array}$ & $\begin{array}{r}6(18.2 \%) \\
16(48.5 \%) \\
11(33.3 \%)\end{array}$ & $\begin{array}{l}18(27.3 \%) \\
28(42.4 \%) \\
20(30.3 \%)\end{array}$ & $\chi^{2}=0.84$ & 0.65 \\
\hline $\begin{array}{l}\text { Incision size } \\
<5 \mathrm{~mm} \\
>8 \mathrm{~mm}\end{array}$ & $\begin{array}{r}6(18.2 \%) \\
27(81.8 \%)\end{array}$ & $\begin{array}{l}10(15.15 \%) \\
56(84.85 \%)\end{array}$ & $\chi^{2}=0.15$ & 0.7 \\
\hline $\begin{array}{l}\text { Use of stay sutures } \\
\text { (for ECCE only) }\end{array}$ & $4 / 28(14.3 \%)$ & $4 / 56(7.14 \%)$ & $\chi^{2}=1.34$ & 0.25 \\
\hline $\begin{array}{l}\text { Capsulotomy used } \\
\text { Beer-can } \\
\text { Envelope } \\
\text { Capsulorhexis }\end{array}$ & $\begin{array}{r}8 / 25(32 \%) \\
11 / 25(44 \%) \\
6 / 25(24 \%)\end{array}$ & $\begin{array}{l}26 / 61(42.7 \%) \\
21 / 61(34.4 \%) \\
14 / 61(23 \%)\end{array}$ & $\chi^{2}=0.95$ & 0.62 \\
\hline $\begin{array}{l}\text { Viscoelastic used } \\
\text { Healon } \\
\text { Ophthalin } \\
\text { Other } \\
\end{array}$ & $\begin{array}{cc}28 / 31 & (90.3 \%) \\
2 / 3 & (6.45 \%) \\
1 / 31 & (3.25 \%) \\
\end{array}$ & $\begin{array}{c}54 / 58(93.1 \%) \\
4 / 58(6.9 \%) \\
0 / 58\end{array}$ & $x^{2}=1.9$ & 0.39 \\
\hline
\end{tabular}

Cases and controls were also matched for operative procedures and these included extracapsular cataract surgery (cases: 19; controls: $38)$, phacoemulsifcation cataract surgery $(6 ; 12)$, pars plana vitrectomy $(2 ; 4)$, trabeculectomy $(1 ; 2)$, combined cataract and filtration surgery $(4 ; 8)$ and external retinal detachment surgery $(1 ; 2)$.

GA, general anaesthesia; LA, local anaesthesia; ECCE, extracapsular cataract extraction.

intraoperative step at which AISH occurred $(p=0.1332)$; grade of operating surgeon $(p=0.17)$; shallowing of the anterior chamber $(p=0.07)$; iris prolapse $(p=0.07)$; loss of red reflex $(p=0.32)$; preceding choroidal effusion $(p=0.51)$; extrusion of intraocular contents $(p=0.07)$.

The various steps taken in the intraoperative period to control the AISH were associated with statistically comparable visual outcomes, and these included wound

Table 3. Visual outcomes in relation to operative procedure, and demographic data, for 45 cases of acute intraoperative suprachoroidal haemorrhage

\begin{tabular}{lccc}
\hline & \multicolumn{3}{c}{ Final Snellen acuity } \\
\cline { 2 - 4 } Procedure & 3 & 4 & 18 \\
\hline $\begin{array}{l}\text { ECCE } \\
(n=25 ; 55.5 \%)\end{array}$ & 4 & 0 & 2 \\
$\begin{array}{l}\text { Phacoemulsification } \\
(n=6 ; 13.3 \%)\end{array}$ & 2 & 1 & 0 \\
$\begin{array}{l}\text { Trabeculectomy } \\
(n=3 ; 6.6 \%)\end{array}$ & 0 & 1 & 5 \\
$\begin{array}{l}\text { Combined cataract and } \\
\text { filtration surgery } \\
(n=6 ; 13.3 \%)\end{array}$ & & & \\
$\begin{array}{l}\text { Pars plana vitrectomy } \\
(n=2 ; 4.44 \%)\end{array}$ & 0 & 1 & 1 \\
$\begin{array}{l}\text { External RD surgery } \\
(n=2 ; 4.44 \%)\end{array}$ & 1 & 0 & 1 \\
$\begin{array}{l}\text { Removal of soft lens matter } \\
(n=1 ; 2.2 \%)\end{array}$ & 0 & 1 & 0 \\
\hline
\end{tabular}

Mean age $\pm S D=74.2 \pm 12.1$ years (range 47-94 years); male:female ratio $=11.34$.

$\mathrm{CF}$, counting fingers; ECCE, extracapsular cataract extraction; External RD surgery, external retinal detachment surgery. closure alone ( $p=0.13)$, drainage of suprachoroidal blood via a sclerostomy $(p=0.15)$ and anterior vitrectomy $(p=0.1)$. Also, when the operative procedures were classed as either cataract surgery, combined surgery, filtration surgery or 'other' there was no statistically

Table 4. Intraoperative clinical details for 45 cases of acute intraoperative suprachoroidal haemorrhage

\begin{tabular}{lr}
\hline Stage of operation at which AISH noted & \\
Entering the eye & $6(15.5 \%)$ \\
Capsulotomy & $6(15.5 \%)$ \\
Phacoemulsification/nuclear expression & $5(11.1 \%)$ \\
After removal of nucleus & $17(37.7 \%)$ \\
Following PC rupture & $2(4.44 \%)$ \\
Clinical signs of AISH & \\
Shallowing of AC & $28(62.2 \%)$ \\
Iris prolapse & $15(33.3 \%)$ \\
Loss of red reflex & $27(60 \%)$ \\
Spontaneous expression of nucleus ${ }^{\mathrm{a}}$ & $9(24.3 \%)$ \\
Preceding choroidal effusion & $21(46.6 \%)$ \\
Extrusion of intraocular contents & $21(46.6 \%)$ \\
Intraoperative measures taken & \\
Wound closure alone & $28(62.2 \%)$ \\
Sclerostomy & $12(26.6 \%)$ \\
Anterior vitrectomy & $14(31.1 \%)$ \\
IV mannitol & $4(8.8 \%)$ \\
IV diamox & $2(4.4 \%)$ \\
Grade of operating surgeon & \\
Senior house officer & $4(8.8 \%)$ \\
Registrar & $13(28.8 \%)$ \\
Senior registrar & $5(11.1 \%)$ \\
Consultant & $23(51.1 \%)$ \\
\hline AISH, acute intraoperative suprachorodal
\end{tabular}

AISH, acute intraoperative suprachoroidal haemorrhage; PC, posterior capsule; $\mathrm{AC}$, anterior chamber; IV, intravenous.

${ }^{\text {a }}$ Cataract surgery only. 


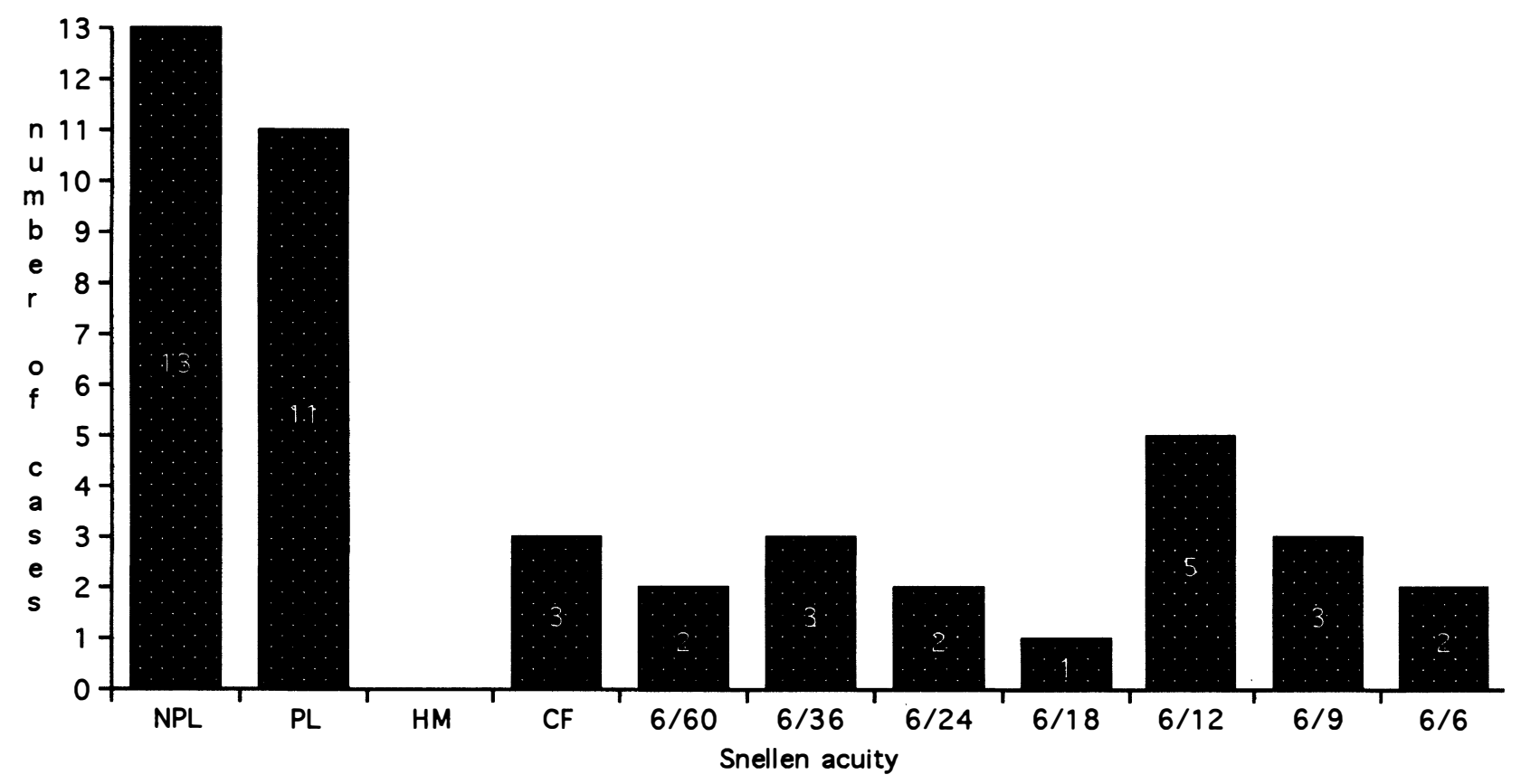

Fig. 1. Histogram of final visual outcomes for 45 cases of acute intraoperative suprachoroidal haemorrhage. NPL, no perception of light; PL, perception of light; HM, hand movements; CF, counting fingers.

demonstrable difference between these groups in terms of visual outcome $(p=0.17)$. Expulsive AISH complicated small-incision ( 2 cases, 33\%) and extracapsular (14 cases, $56 \%$ ) cataract surgeries with statistically comparable frequencies $(p=0.39)$. However, a favourable visual outcome was found to be significantly more likely in cases of AISH complicating phacoemulsification surgery $(p=0.03)$, or any procedure where the incision size was less than $5 \mathrm{~mm}(p=0.01)$. When AISH affecting extracapsular cataract extraction and phacoemulsification cataract surgery were directly compared, a final acuity of $6 / 12$ or better was found to be significantly more likely in those eyes that had undergone small-incision cataract surgery $(p=0.004)$.

Per-operative and post-operative findings associated with a poor visual result (CF or worse) included spontaneous nuclear expression $(p=0.02)$, retinal detachment $(p<0.0001)$, a Snellen acuity of perception of light (PL) or worse at the first dressing $(p=0.0001)$ and involvement of four quadrants by the suprachoroidal haemorrhage or effusion $(p=0.007)$. Expulsive cases were also found to be at significantly greater risk of a poor visual outcome $(p=0.04)$.

Ocular B-scan echography was performed in 18 cases in the early post-operative period. Of these, blood was demonstrable in the suprachoroidal space in 13 cases $(72.2 \%)$, and choroidal effusion was seen in the remaining 5. A final acuity of CF or worse was seen in 5 of the 13 cases of ultrasonographically confirmed suprachoroidal haemorrhage (38\%) compared with only 1 of the 5 cases of choroidal effusion $(20 \%)$, but this difference did not reach statistical significance $(p=0.6)$.
Fifteen eyes underwent secondary surgical procedures and these included retinal detachment repairs (7), drainage of suprachoroidal blood (4), insertion of an intraocular lens (2), redo cataract surgery (1) and enucleation (1). All secondary operations were uneventful.

Ocular findings at the last ophthalmic assessment included: phthisis bulbi (14); cellophane maculopathy (8); retinal detachment (4); cataract (3); vitreous haemorrhage (5); cystoid macular oedema (1); aphakia (1); macular hole (1). Nothing untoward was noted in 8 eyes.

\section{Discussion}

AISH is a rare but well described complication of ophthalmic surgery. It has been reported in association with phacoemulsification and extracapsular cataract surgery, ${ }^{4,8}$ trabeculectomy, ${ }^{9,10}$ pars plana vitrectomy, ${ }^{11,12}$ penetrating keratoplasty, ${ }^{13,14}$ and scleral buckling surgery. ${ }^{15}$ The incidence of this potentially blinding event depends on the operative procedure it complicates, and is said to occur in $0.2-0.9 \%$ of cataract operations. ${ }^{4,5,16,17}$

AISH is the result of bleeding into the suprachoroidal space that occurs when there is a dramatic drop in IOP. A fall in IOP, and consequently a loss of the normal physiological equilibrium that forces blood from the choroid into the vortex veins, results in transudation of fluid into the suprachoroidal space. This separation of choroid from sclera exerts a shearing force on blood vessels as they enter the suprachoroidal space, and a small amount of haemorrhage ensues. If the choroidal effusion and haemorrhage extend anteriorly, detachment 
of the ciliary body and tearing of the ciliary body vessels results in profuse bleeding and massive suprachoroidal haemorrhage. ${ }^{18,19}$ Therefore, factors that might reasonably be suspected of predisposing to AISH include a profound drop in IOP (e.g. high pre-operative IOP), choroidal vascular engorgement (e.g. retrobulbar/ peribulbar anaesthesia) and arteriosclerotic vasculature (e.g. generalised atheromatous disease, hypertension).

We found that cases and their gender- and sexmatched controls differed only in terms of axial length and last recorded pre-operative IOP, which were significantly greater in the AISH group. These two ocular characteristics have previously been identified as risk factors for suprachoroidal haemorrhage. ${ }^{10}$ Increased axial length is thought to contribute to the overall risk because of its associated choroidal vascular fragility, ${ }^{10}$ whereas a more dramatic drop in IOP is experienced intraoperatively in those eyes with a higher pre-operative IOP. Although other previously reported risk factors for AISH such as hypertension, generalised atherosclerosis, ${ }^{10}$ chronic obstructive airways disease, glaucoma, ${ }^{10}$ retrobulbar anaesthesia and use of anticoagulant or anti-platelet therapy ${ }^{5}$ were more common in our cases than controls, these differences did not reach statistical significance.

A favourable final visual outcome of $6 / 12$ or better was achieved in 10 eyes (22.2\%), and this is comparable to the results of the larger series reported in the literature. ${ }^{9,10}$ It is worth noting, however, that this level of post-operative vision has been described in $84-93 \%$ of AISH cases by two high-volume cataract surgeons reporting on their own results. ${ }^{4,5}$ The excellent results in those two articles appear to reflect the inclusion of a large number of limited choroidal haemorrhages and effusions, indicated by the small number of truly expulsive cases, and the surgeons' ability to bring surgery to a rapid conclusion. ${ }^{4,5,20-22}$ In the present study, however, final visual outcome did not differ significantly between surgeons of varying experience.

The only feature of AISH presentation that we found to be indicative of a poor visual prognosis was spontaneous nuclear expression, which occurs as a result of massive and vigorous suprachoroidal haemorrhage. Findings on the first post-operative day that were associated with a final acuity of CF or worse included retinal detachment, vision of PL or NPL or $360^{\circ}$ involvement by the suprachoroidal bleed. Some of these poor prognostic indicators, such as retinal detachment and four-quadrant suprachoroidal haemorrhage, have been described previously. ${ }^{9,23}$ These findings further emphasise the role of B-scan echography in assisting the ophthalmic surgeon to furnish the patient with a realistic visual prognosis in the early post-operative period.

To our knowledge there have been no studies specifically designed to compare the incidence of AISH in extracapsular and phacoemulsification cataract surgery, and it was not the aim of this study. Two reports have commented that AISH complicates the two surgical techniques with a similar frequency, ${ }^{4,10}$ whereas another article reports an AISH rate of $0.5 \%$ and $4 \%$ in small- incision and nuclear expression cataract surgeries respectively. ${ }^{5}$ Blumenthal et al. ${ }^{24}$ demonstrated a drop in the incidence of AISH from $0.25 \%$ to 0 by maintaining positive IOP for the duration of the procedure using an anterior chamber maintainer. However, there have been no published comparative analyses of visual outcomes following AISH complicating the two types of operation. We found that a favourable visual outcome was significantly more likely for eyes that experienced an AISH during phacoemulsification surgery (two-thirds achieved a final acuity of $6 / 12$ or better) than during extracapsular cataract surgery. This finding is not surprising when one considers that the most important step in intraoperative management is to stop bleeding by tamponade. Wound closure is more rapidly achieved in the presence of a small, self-sealing incision than with a full-sized extracapsular wound, and consequently the suprachoroidal haemorrhage will not extend.

Furthermore, AISH complicating small-incision cataract surgery tends to be limited because actual extrusion of intraocular contents is less likely and spontaneous nuclear expression is impossible. ${ }^{25}$

Optimum visual outcome following AISH depends on its early recognition, and prompt closure of the wound without incarceration of iris and vitreous. ${ }^{4,5,9,26,27}$ If the eye cannot be closed effectively, a posterior sclerotomy to drain suprachoroidal blood is indicated. This opening should be quite posterior and at least $1.5 \mathrm{~mm}$ in diameter if the haemorrhage is to be successfully evacuated. ${ }^{28}$ Post-operative care includes adequate control of IOP and use of a topical antibiotic-corticosteroid preparation. Some investigators have recommended the use of highdose oral steroids in an attempt to reduce post-operative inflammation and vascularity. ${ }^{29}$ Ocular B-scan echography is indicated to evaluate the extent of the suprachoroidal bleed, and to monitor progression of clot lysis. ${ }^{30}$ A massive suprachoroidal haemorrhage, defined as one of sufficient volume to force the inner retinal surfaces into apposition, is an indication for early secondary surgical intervention in the form of posterior drainage sclerotomies under constant infusion pressure. ${ }^{31-33}$ However, this procedure should be delayed until liquefaction of the blood clot is complete. ${ }^{32}$ Other complications of AISH, including retinal detachment, should be treated on their own merits. Several investigators have concluded that eyes that have experienced an AISH can be re-entered safely at a later date. ${ }^{4,34}$

In conclusion, the results of this study confirm that increased axial length and pre-operative intraocular pressure are risk factors for acute intraoperative suprachoroidal haemorrhage. Intraoperative and postoperative indicators of a poor visual outcome include spontaneous nuclear expression, retinal detachment, four-quadrant suprachoroidal haemorrhage and an acuity of perception of light or worse at the first dressing. Our results also indicate that AISH has a more favourable visual prognosis if it occurs during a phacoemulsification procedure rather than during extracapsular cataract surgery. 


\section{References}

1. Manshot WA. The pathology of expulsive haemorrhage. Am J Ophthalmol 1955;40:15-23.

2. Perry HD, Hsieh RC, Evans RM. Malignant melanoma of the choroid associated with spontaneous expulsive choroidal haemorrhage. Am J Ophthalmol 1977;84:205-8.

3. van Meurs JC, van den Bosch WA. Suprachoroidal haemorrhage following a Valsalva maneuver. Arch Ophthalmol 1993;111:1025-6.

4. Davison JA. Acute intraoperative suprachoroidal hemorrhage in extracapsular cataract surgery. J Cataract Refract Surg 1986;12:606-22.

5. Arnold PN. Study of acute intraoperative suprachoroidal hemorrhage. J Cataract Refract Surg 1992;18:489-94.

6. Ruderman JM, Harbin TS, Campbell DG. Postoperative suprachoroidal hemorrhage following filtration procedures. Arch Ophthalmol 1986;104:201-5.

7. Frenkel REP, Shin DH. Prevention and management of delayed suprachoroidal hemorrhage after filtration surgery. Arch Ophthalmol 1986;104:1459-63.

8. Davison JA. Acute intraoperative suprachoroidal hemorrhage in capsular bag phacoemulsification. J Cataract Refract Surg 1993;19:534-7.

9. Reynolds MG, Haimovici R, Flynn HW, DiBernardo C, Frazier-Byrne S, Feuer W. Suprachoroidal hemorrhage: clinical features and results of secondary surgical management. Ophthalmology 1993;100:460-5.

10. Speaker MG, Guerrierio PN, Met JA, Coad CT, Berger A Marmor M. A case-control study of risk-factors for intraoperative suprachoroidal expulsive hemorrhage. Ophthalmology 1991;98:202-10.

11. Lakhanpal V, Schocket SS, Elman MJ, Dogra AR. Intraoperative massive suprachoroidal hemorrhage during pars plana vitrectomy. Ophthalmology 1990;97:1114-9.

12. Piper JG, Han DP, Abrams GW, Mieler WF. Perioperative choroidal hemorrhage at pars plana vitrectomy: a casecontrol study. Ophthalmology 1993;100:699-704.

13. Ingraham HJ, Donnenfeld ED, Perry HD. Massive suprachoroidal hemorrhage in penetrating keratoplasty. Am J Ophthalmol 1989;108:670-5.

14. Price FW, Whitson WE, Ahad KA, Tavakkoli $\mathrm{H}$. Suprachoroidal hemorrhage in penetrating keratoplasty. Ophthalmic Surg 1994;25:521-5.

15. Fastenberg DM, Perry HD, Donnenfeld ED, Schwartz PL, Shakin JL. Expulsive suprachoroidal hemorrhage with scleral buckling surgery. Arch Ophthalmol 1991;109:323.

16. Taylor DM. Expulsive hemorrhage. Am J Ophthalmol 1974;78:961-6.

17. Payne JW, Kameen AJ, Jensen AD, Christy NE. Expulsive hemorrhage: its incidence in cataract surgery and a report of four bilateral cases. Trans Am Ophthalmol Soc 1985;83:181-204.
18. Wolter JR, Garfinkel RA. Ciliochoroidal effusion as precursor of suprachoroidal hemorrhage: a pathologic study. Ophthalmic Surg 1988;19:344-9.

19. Beyer CF, Peyman GA, Hill JM. Expulsive choroidal hemorrhage in rabbits: a histopathologic study. Arch Ophthalmol 1989;107:1648-53.

20. Maumenee AE, Schwartz MF. Acute intraoperative choroidal effusion. Am J Ophthalmol 1985;100:147-54.

21. Hoffmann P, Pollack A, Oliver M. Limited choroidal hemorrhage associated with extracapsular cataract extraction. Arch Ophthalmol 1984;102:1761-5.

22. Bukelman A, Hoffman P, Oliver M. Limited choroidal hemorrhage associated with extracapsular cataract extraction. Arch Ophthalmol 1987;105:338-41.

23. Welch JC, Spaeth GL, Benson WE. Massive suprachoroidal hemorrhage: follow-up and outcome of 30 cases. Ophthalmology 1988;95:1202-6.

24. Blumenthal M, Grinbaum A, Assia EI. Preventing expulsive hemorrhage using an anterior chamber maintainer to eliminate hypotony. J Cataract Refract Surg 1997;23:476-9.

25. Elliot AJ. Expulsive haemorrhage during phacoemulsification. Eye 1993;7:598-9.

26. Spaeth GL. Suprachoroidal hemorrhage: no longer a disaster. Ophthalmic Surg 1987;18:329-30.

27. Whitehouse GM, Filipic M, Francis IC. Expulsive choroidal haemorrhage: a clinical and pathological review. Aust NZ J Ophthalmol 1989;17:225-32.

28. Dellaporta A. Scleral trephination for subchoroidal effusion. Arch Ophthalmol 1983;101:1917-9.

29. Lambrou FH Jr, Meredith TA, Kaplan HJ. Secondary surgical management of expulsive choroidal hemorrhage. Arch Ophthalmol 1987;105:1195-8.

30. Chu TG, Cano MR, Green RL, Liggett PE, Lean JS. Massive suprachoroidal hemorrhage with central retinal apposition: a clinical and echographic study. Arch Ophthalmol 1995;109:1575-81.

31. Le Mer Y, Renard Y, Allagui M. Secondary management of suprachoroidal hemorrhages. Graefes Arch Clin Exp Ophthalmol 1993;231:351-3.

32. Lakhanpal V, Schodket SS, Elman MJ, Nirankari VS. A new modified vitreoretinal surgical approach in the management of massive suprachoroidal hemorrhage. Ophthalmology 1989;96:793-800.

33. Abrams GW, Thomas MA, Williams GA, Burton TC. Management of postoperative suprachoroidal hemorrhage with continuous-infusion air pump. Arch Ophthalmol 1986;104:1455-8.

34. Bryant WR. Secondary intraocular lens implantation in eyes that experienced suprachoroidal hemorrhage during primary cataract surgery. J Cataract Refract Surg 1989;15:629-34. 